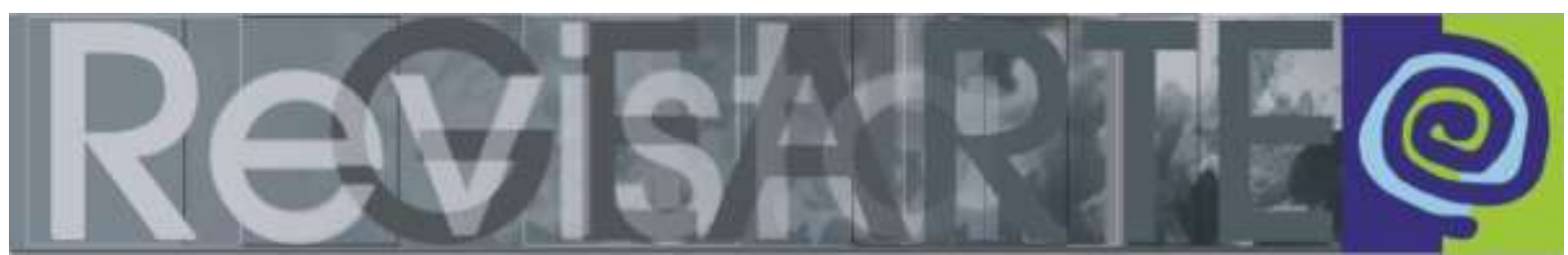

ISSN 2357-9854

\title{
Leitura visual: arte, mídia e cotidiano
}

Como ler imagens, produções imagéticas criadas a partir de uma ou de várias linguagens? Que leituras fazemos das imagens da arte, da mídia e do cotidiano? O que essas imagens mostram e como mostram? Como a leitura visual nos afeta?

Para Eisner (2002, p. 54), uma das importantes contribuições das artes visuais para a educação refere-se a "ajudar os estudantes a aprender a 'ler' o mundo visual a partir de um referencial artístico". Concordamos com o autor quando diz que a arteeducação, ao prover referenciais visuais aos estudantes, tem a ver com a expansão dos modos de ver e experimentar o mundo.

Há mais de três décadas, estudos sobre leitura visual têm levantado não só questões conceituais acerca desse tema - que abarcam, em especial, os campos das artes visuais, da semiótica, da cultura visual e do ensino da arte - mas também modos de propor práticas de leitura de imagens em contextos de educação formal e não formal. Tais estudos procuram entender como produzimos sentido a partir do que as imagens mostram, bem como das nossas competências de leitura e do contexto em que estamos inscritos. Ainda, referem que as imagens com as quais interagimos nos constituem como sujeitos de uma época e lugar.

Jorge Larrosa (1996, p. 16) aborda a leitura como uma atividade que tem a ver com a subjetividade do leitor; não só com o que o leitor sabe, senão com o que é. O autor diz que a leitura "não é só um passatempo, um mecanismo de evasão do mundo real e do eu real. E não se reduz tampouco a um meio para adquirir conhecimentos. (...) essa misteriosa atividade que é a leitura tem a ver com aquilo que nos faz ser o que somos". Em outras palavras, a leitura produz a subjetividade. Quando 
transcendemos a simples busca de informação ou erudição na leitura estética permitimos que os textos nos transformem e nos constituam.

Para o presente número da Revista Gearte - Leitura Visual: arte, mídia e cotidiano - foram selecionados trabalhos que revelam a contemporânea pluralidade de olhares sobre distintos objetos de análise. Como característica em comum, trazem consigo um desejo de perscrutar, analisar e construir efeitos de sentido a partir de elementos presentes na arte e na mídia, mas sobretudo no cotidiano.

Humberto Nuno de Oliveira e Sandra Ramalho e Oliveira, no texto O simbólico e o semi-simbólico: no entrecruzamento de duas propostas para a leitura do brasão do Papa Francisco, estabelecem um interessante diálogo entre dois campos teóricos distintos - a heráldica e a semiótica visual - através da leitura do brasão do Papa Francisco. Trata-se de diferentes perspectivas a ler um mesmo objeto: a heráldica, abordando a imagem do brasão como um sistema simbólico, com significados convencionados a cada um dos elementos; e a semiótica, considerando-o como um sistema semi-simbólico, em que não há uma relação direta entre os elementos isolados dos planos de expressão e de conteúdo, mas entre categorias da expressão e categorias do conteúdo. Por fim, os autores buscam pontos de contato entre as duas análises a partir de três categorias, a saber, o escudo, as cores e os elementos externos. É ressaltada no texto a metalinguística comum, partilhada pelos autores, que orientou os dois crivos de leitura com base numa matriz cristã.

Em O conhecimento secreto de David Hockney e as múltiplas janelas de tempo nos desenhos de Jandira Lorenz, Sandra Makowiecky e Vanessa de Oliveira utilizam as proposições teóricas desenvolvidas por David Hockney - apresentadas no livro $O$ conhecimento secreto: redescobrindo as técnicas perdidas dos grandes mestres para analisar o trabalho da artista plástica Jandira Lorenz. O estudo de Hockney mostra como inúmeros artistas ocidentais, desde o século $\mathrm{XV}$, fizeram uso de instrumentos ópticos para apreender e representar a realidade, partindo da representação do detalhe isolado para então compor a obra, como em uma montagem. Esse processo foi denominado por Hockney de "janelas múltiplas" conceito utilizado por Makowiecky e Oliveira para analisarem os desenhos de Jandira Lorenz. As autoras realizam então uma "desmontagem" de uma obra da artista, 
destacando, em múltiplas janelas, elementos diversos e várias imagens dentro de uma imagem, desvelando, assim, o trajeto memorial dessa composição artística.

Letícia Nassar Matos Mesquita e Moema Lucia Martins Rebouças trazem no artigo Relação entre verbal e visual na construção do discurso prescritivo na revista Capricho parte da pesquisa em que analisam como a Capricho - atualmente a maior revista destinada ao público feminino juvenil em circulação no país - constrói um discurso que indica à adolescente modos de ser e parecer que devem ser seguidos para ser aceita em seus grupos sociais. A partir da análise da capa e de duas seções da revista - Busca e Look - as autoras apresentam o estudo das estratégias enunciativas e dos objetos investidos de valor colocados em circulação pela revista, de modo a persuadir a leitora a "adquirir a revista, acreditar no que está sendo dito e agir de acordo com o que é proposto".

No texto Tanto vilão quanto herói: a estética do novo protagonista dos contos de fadas Ana Mery De Carli e Karem Sartor dos Santos abordam as diferenças entre padrões culturais e comportamentos sociais da modernidade e da pós-modernidade, por meio da análise comparativa de duas adaptações cinematográficas do conto de fadas "A Bela Adormecida" - a animação homônima de 1959 e "Malévola", um filme de 2014, ambas dos Estúdios Disney. As autoras apontam a presença da polarização entre o bem e o mal nas histórias ficcionais até a primeira metade do século XX e o seu abandono na contemporaneidade. Como exemplo da presença dessa polarização, as autoras trazem "A Bela Adormecida" (animação), analisando a representação estereotipada de personagens do bem e do mal. Por sua vez, o abandono do dualismo nas produções contemporâneas é exemplificado com "Malévola" - tanto vilã quanto heroína - que oscila entre o bem e o mal, constituindose numa personagem ambivalente e contraditória. Contextualizando a estética/cultura pós-moderna, o texto permite ao leitor acompanhar a abertura da "identidade para as identificações múltiplas", para o contraditório, para o plural (MAFFESOLI) e descobrir novos modos de dar sentido aos produtos culturais contemporâneos.

Em Aurora, um jogo visual de luz e cores, Neiva Senaide Petry Panozzo nos conduz na leitura semiótica do livro de imagem "Aurora" de Cristina Biazetto publicado pela Editora Projeto (2009), pertencente ao acervo de 2012 do Programa Nacional de 
Biblioteca Escolar (PNBE). Considerado como objeto literário e estético, o livro de imagem, ao mesmo tempo em que organiza uma narrativa por meio da linguagem visual, apresenta-se como objeto propício à leitura estética. As possibilidades interpretativas desse texto visual "envolvem um complexo jogo entre seus componentes", nas palavras de Panozzo. Com base na semiótica discursiva e contribuições de Barros, Martín-Barbero e Propp, a autora procura descobrir possibilidades de efeitos de sentido que as qualidades sensíveis das imagens criam nas inter-relações entre os planos de expressão e de conteúdo da obra. O artigo reitera a importância do livro de imagem como objeto de significação e de comunicação e de sua leitura no e para além do contexto escolar.

Em Aproximações com a semiótica discursiva para uma leitura da obra "Contestado - Terra Contestada”, Rita Inês Petrykowski Peixe utiliza os subsídios teóricos da semiótica discursiva para analisar a obra de arte "Contestado: Terra Contestada", de Hiedy de Assis (Hassis), artista catarinense. A obra faz referência à Guerra do Contestado, conflito entre sertanejos e militares gerado da disputa por terras, que ocorreu na fronteira entre os estados de Santa Catarina e Paraná no início do século XX. Conforme a autora, o mural pintado por Hassis não passa despercebido no Museu do Contestado em Caçador (SC) e isso acontece não apenas por seu tamanho imponente (36m de comprimento), mas, principalmente, pelo impacto que a temática gera no espectador: o massacre da população sertaneja. A autora analisa como a leitura do contexto histórico da Guerra se faz presente na obra de Hassis e, ainda, aponta a temática da morte como privilegiada nesse texto visual. Por fim, deixa um convite para concebermos a obra não apenas como "relato visual" da História, mas como geradora de sentidos outros.

O ensaio visual de Rita Demarchi intitulado Na paisagem contemporânea enfoca elementos - imagens e palavras - oriundos de sua pesquisa de doutoramento, na qual utilizou a fotografia como ferramenta para "ver aquele que vê" a arte. Através do ato fotográfico, Demarchi busca prestar atenção, aproximar-se e entender os visitantes de museus, no Brasil e no exterior, sem com eles trocar uma palavra sequer. As fotografias que compõem esse ensaio evidenciam a relação da pesquisadora com 
os visitantes dos espaços de arte e, ao mesmo tempo, revelam modos de interação com as obras de arte.

Analice Dutra Pillar, Maria Helena Wagner Rossi, Rosana Fachel de Medeiros e Ruth Rejane Perleberg Lerm

(Organizadoras)

\section{Referências}

EISNER, Elliot. Ocho importantes condiciones para la enseñanza y el aprendizaje en las artes visuales. Arte, Individuo y Sociedad, anejo I, p. 47-55, 2002.

LARROSA, Jorge. La experiencia de la lectura. Barcelona: Laertes, 1996. 